\title{
17. DE CÓMO OPERA EN LA PRÁCTICA EL MANDO MILITAR DEL REY
}

\author{
JOSE M. ${ }^{a}$ LAFUENTE BALLE \\ Profesor Titular de Derecho Constitucional \\ Universidad de Girona
}




\section{SUMARIO}

I. Doctrina ReCIENTE.-II. La tesis de Ignacio de OTto.-III. La OPERAtiva práctica de la Jefatura Militar del Rey.-IV. ¿UNa reforma del ART. 62.h? 


\title{
17. DE CÓMO OPERA EN LA PRÁCTICA EL MANDO MILITAR DEL REY
}

\author{
POR \\ JOSÉ M. ${ }^{a}$ LAFUENTE BALLE \\ Profesor Titular de Derecho Constitucional \\ Universidad de Girona
}

La interpretación del art. 62.h de la Constitución («Corresponde al Rey... El mando supremo de las Fuerzas Armadas") ha dividido radicalmente a la doctrina constitucionalista. Ya con motivo de la publicación de mi trabajo sobre la Comandancia militar del Rey ', intenté sistematizar los argumentos argüidos por cada uno de los dos sectores doctrinales: uno, mayoritario, partidario de sostener que la Comandancia militar del Rey es de carácter "eminente", es decir, meramente simbólica y honorífica. Frente a esta postura, otros autores han defendido el carácter "efectivo", real y ejecutivo, de la Comandancia militar regia.

Los partidarios de la tesis del carácter eminente de la Comandancia militar del Rey arguyen dos razones fundamentales: la constitucionalización de la forma monárquica de gobierno parlamentario en el art. 1.3, y, que como principio caracterizador de esta forma de gobierno, la regulación de la institución del refrendo ministerial como un acto desigual de predominio gubernamental (arts. 56.3 y 64).

La constitucionalización de la Monarquía parlamentaria como forma de gobierno implica, de una parte, que el Rey vea reducida su función politica a una mera magistratura moral, de manera que el cuadro competencial que se le atribuye -incluido el mando supremo de las Fuerzas Arma-

1 José M. ${ }^{a}$ LAfUeNTE Balle: El Rey y las Fuerzas Armadas en la Constitución. Madrid. Edersa, 1987, págs. 361 a 385. 
das - sea de carácter meramente eminente, y, de otra, que sea el Gobierno el que efectivamente ejercite la función ejecutiva, incluida la Administración militar y la defensa del Estado (art. 97).

Por lo que se refiere a la institución del refrendo ministerial a la que están sujetos todos los actos del Rey, la regulación constitucional al respecto evidencia el predominio del acto gubernamental sobre el acto regio, en cuanto que dispone el traspaso al Gobierno de la responsabilidad política del acto y, por tanto, del poder decisorio del mismo. Consecuentemente, el acto regio, a solicitud del Gobierno, no puede ser sino un acto debido.

Entre los autores partidarios de la tesis del carácter efectivo de la Comandancia militar regia destacan especialmente Luis SÁNCHEZ AGESTA ${ }^{2}$ y Miguel HERRERO R. DE MIÑÓN ${ }^{3}$. A tal efecto, argumentan la rotunda literalidad del art. 62.h de la Constitución ("Corresponde al Rey... El mando supremo de las Fuerzas Armadas"), y su alineamiento con la tesis clásica del refrendo como acto complejo e igual que ya formuló el Prof. VAN DER POT 4. Según esta teoría, en la formación del acto regio refrendado intervienen dos competencias ...regia y ministerial... independientes y mutuamente garantes, de forma que la decisión tiene carácter unitario. Así, mientras corresponde a la competencia del Rey el prudente ejercicio de sus competencias constitucionales, corresponde a los ministros el refrendo de la voluntad regia - y no sólo la aprobación de la forma del acto regio-, de manera que no pueden suplir - sustituir o forzar- los actos y opiniones del Rey.

\section{DOCTRINA RECIENTE}

La dogmática constitucionalista publicada en los últimos cinco años no ha variado su tendencia favorable a la tesis del carácter eminente de la Comandancia militar regia.

2 Luis SÁNCHEZ AgeSta: Sistema político de la Constitución española de 1978. Madrid. Edersa.

3 Miguel HerRero R. DE MiÑón: El Rey y las Fuerzas Armadas, en Revista del Departamento de Derecho Político, n. ${ }^{\circ} 7,1980$, págs. 39 a 56 . Madrid, Universidad Nacional de Educación a Distancia.

4 C.N. VAN DER POT: Handboek van het Nederlandse Staatsrecht. W.E.J. Tjeenk Willink. Zwolle, 1977, págs. 249, 250 y 251. V. también Manuel JIMÉNEZ DE PARGa y CABRERA: Las Monarquías europeas en el horizonte español. Madrid. Ed. Tecnos, 1966, págs. 135 a 148. 
Partidarios de esta tesis se han manifestado los Profs. GARCIA CANALES ${ }^{5}$ y FREIXES SANJUÁN: "El poder auténtico que la Corona tenía sobre las Fuerzas Armadas se ha transformado en una atribución simbólica al adquirir el Gobierno la dirección de la política de defensa y el mando efectivo de los ejércitos" ${ }^{6}$. Más profundamente, el Prof. LÓPEZ RAMÓN ${ }^{7}$ razona su apoyo a esta tesis argumentado el fundamento del sistema constitucional español en el principio democrático del art. 1.1 y en que el refrendo supone el traslado del poder de decisión al refrendante.

En el prólogo del libro de Fernando LÓPEZ RAMÓN, el Prof. GARCÍA DE ENTERRÍA ${ }^{8}$ contradice la postura del autor prologado: «Me permitiré notar que quizá aquí hubiese sido oportuna alguna reserva sobre la función propia del monarca, que, a mi juicio, no alcanza a explicar plenamente su sola condición de símbolo", e identifica la facultad regia de la Comandancia militar con las royal prerogatives de la Constitución británica: "Pero en el papel del Rey me parece difícil no ver, además, una suerte de reserva última de poder..., reserva virtual que no hace falta que esté demasiado expresa... y que podría, en último extremo, derivar de la sola forma monárquica constitucional, como forma política que prima una cierta continuidad histórica». Así, para ejemplificar su argumentación, se refiere al origen de la Constitución y a la rebelión militar del 23 de febrero de 1981 como dos momentos en los que ese poder de reserva regio habría jugado un papel trascendental.

Reafirmando su adscripción a la tesis efectiva de la Comandancia militar regia, Miguel HERRERO R. DE MIÑóN ${ }^{9}$ reitera su teoría de que los arts. 56.1 y $62 . h$ configuran al Rey, "por la independencia, objetividad y permanencia de sus funciones, por la individualidad de su magistraturan,

5 Mariano García Canales: La Monarquía parlamentaria española. Madrid. Ed. Tecnos. 1991. págs. 205 a 206.

6 Teresa Freixes SANJUÁN: "La Jefatura del Estado monárquica», en Revista de Estudios Políticos, n. ${ }^{\circ} 73$, junio-septiembre 1991. págs. 105 a 107. Madrid. C.E.C.

7 Fernando López RAMón: La caracterización jurídica de las Fuerzas Armadas. Madrid, Centro de Estudios Constitucionales, 1987, págs. 354 a 361; y «Principios de la Ordenación constitucional de las Fuerzas Armadas", en Estudios sobre la Constitución Española. Homenaje al prof. Eduardo GARCIA DE ENTERRIA. Madrid. Ed. Civitas. 1991, T. III, págs. 2577 a 2580.

8 Eduardo Garcia de Enterría: Prólogo a Fernando López Ramón: La caracterización jurídica de las Fuerzas Armadas. Madrid. C.E.C., 1987, págs. XXI a XXIV. Tiempo después el Prof. LóPEz RAMón (La caracterización... cit, pág. 2580) afirma escuetamente que la postura del Prof. GARCIA DE ENTERRÍA completa la suya, si bien no explica cómo resuelve esta aparente contradicción.

9 Miguel Herrero R. DE MiÑón: "La Posición constitucional de la Corona", en Estudios sobre la Constitución española. Homenaje al Prof. Eduardo GARCíA DE ENTERRIA. Madrid. Ed. Civitas. 1991. T. III, págs. 1936 a 1939. 
en el instrumento constitucional con mejores condiciones para garantizar la defensa política de la Constitución en el supuesto extremo de que el ordenamiento constitucional o la existencia de la Nación o del Estado se encuentren de tal manera amenazados que la capacidad de autorreglaje de los poderes públicos resulte insuficiente.

\section{LA TESIS DE IGNACIO DE OTTO}

Especial interés reviste, a mi entender, por su novedad, la tesis del Prof. DE OTTO y PARDO ${ }^{10}$. Para este autor, el art. 62. $h$ de la Constitución atribuye al Rey una competencia singular y efectiva. En defensa de esta postura, arguye argumentos no sólo jurídicos, sino también históricos $y$ sociológicos de opinión pública ${ }^{11}$.

Este trabajo parte de una clasificación de los contenidos posibles de la facultad del mando supremo de las Fuerzas Armadas. En este sentido distingue, de una parte, un doble contenido ad extra: político y militar; $y$, de otra parte, un doble contenido ad intra: la competencia propia del comandante sobre su unidad $u$ organismo militar y la potestad propia del superior jerárquico para dar órdenes a un inferior jerárquico ajeno a su unidad.

Pues bien, para el Prof. DE OTTO Y PARDO ni el mando político ni el militar corresponden al Rey, sino al Gobierno en virtud del texto del art. 97 de la Constitución. Tampoco ostenta el Rey competencia de mando alguna porque, de otra manera, en su gestión sobre su unidad, estaría subordinado a la dirección del Gobierno (art. 97 de la Constitución).

En fin, este autor defiende que el art. 62.h de la Constitución atribuye al Rey, en cuanto que primer oficial del Ejército investido del grado máximo de autoridad, la potestad de dar órdenes de servicio y de ejecución, cuyo ejercicio, por su forma verbal, quedaría exceptuado de la exigencia de refrendo.

10 Ignacio DE OTTO Y PARDO: "El mando supremo de las Fuerzas Armadas", en Revista Española de Derecho Constitucional, n. ${ }^{\circ} 23$, mayo-agosto 1988, págs. 11 a 43. Madrid C.E.C. Aparentemente coincidentes con esta tesis, se manifiestan Manuel Fernández-Fontecha Torres y Alfredo Pérez de Armiñán y de la Serna: La Monarquia y la Constitución. Madrid. Ed. Civitas, págs. 362 a 363.

11 V. en el mismo sentido Antonio Pérez Henares, Carlos A. Malo de Molina y Enrique CURIEL: Luces y sombras del poder militar en España. Madrid. Ed. Temas de hoy. 1989, págs. 146 a 157. 
En mi opinión, la tesis del Prof. DE OTTO Y PARDO no es aceptable porque su razonamiento padece de un defecto lógico. Para que la potestad de dar órdenes a los militares de inferior graduación derivase del art. 62. $h$ de la Constitución sería preciso que este precepto atribuyese al Rey el título que le legitimase para ejercer esa potestad, es decir, la alta graduación militar que precisaría para dar órdenes a los inferiores. Sin embargo, su alta graduación militar, como Capitán General, no tiene fundamento constitucional, sino legal, concretamente el Decreto-Ley 16/1975 de 20 de noviembre.

El art. 62.h de la Constitución atribuye al Rey una facultad, no un grado militar. Coincido con el Prof. DE OTTO Y PARDO en que el Rey tiene la potestad de dar órdenes a los militares de graduación inferior a la suya pero el fundamento legal de esta potestad no es constitucional sino subconstitucional.

Por otra parte, no me parece un argumento admisible que la forma verbal de un acto regio sea razón suficiente para exceptuarlo de la exigencia del refrendo. Antes al contrario, para este tipo de actos procede el denominado refrendo tácito que, para las órdenes militares del Rey, correspondería a la competencia del Ministro de Defensa.

Aun cuando su publicación es anterior en el tiempo, el manual del Prof. TORRES DEL MORAL 12 parece contradecir la teoría del Prof. DE OTTO Y PARDO, cuando afirma que aunque en la realidad política las Fuerzas Armadas se someten al Rey, este hecho revela solamente la falta de consolidación del sistema constitucional: "En fin, no deja de ser cierto lo que reiteradamente se ha apuntado: que en el terreno de la realidad política, las Fuerzas Armadas se someten al Rey mejor que al Gobierno, lo que convierte, de hecho, la comandancia militar regia en efectiva. Pero, en la medida en que esto sucede todavía, en esa misma medida puede decirse que el régimen constitucional español no está plenamente consolidado, pues ello ocurre, sí, de hecho, más no de Derecho".

\section{LA OPERATIVA PRÁCTICA DE LA JEFATURA MILITAR DEL REY}

No me parece cuestionable que la Comandancia militar del Rey tenga un alcance meramente eminente, es decir honorífico. La tesis eminente encuentra un sólido fundamento legal tanto en la constitucionalización de

12 Antonio Torres del Moral: Principios de Derecho Constitucional. Madrid. Átomo Ed. 1988, vol. 2, págs. 46 a 51 . 
la forma monárquica de gobierno parlamentario del art. 1.3., como en la regulación de la institución del refrendo ministerial como un acto desigual de predominio gubernamental. Por otra parte, el art. 97 atribuye de forma expresa al Gobierno el ejercicio de la función ejecutiva y, concretamente, la dirección de la Administración militar y la defensa del Estado.

Consecuentemente, la facultad regia de la Comandancia militar se ve reducida al ejercicio del poder moderador (art. 56.1) por parte del Rey en el proceso de formación de la voluntad del Gobierno - en cuanto que verdadero titular de la facultad regia- previo al dictado de la orden de comandancia militar.

Ello no obstante, la práctica de la operativa de las órdenes de comandancia militar ha dotado a la facultad regia de cierta dimensión efectiva. Me refiero a la convención constitucional de la potestad regia de la iniciativa del acto. Insístase en que no se trata de una quiebra de la tesis eminente, sino de un mecanismo eficaz para el ejercicio por el Rey de su poder moderador.

Ya en el verano de 1983, el Secretario General de la Casa Real ${ }^{13}$ me aseguró que era práctica habitual del Rey proponer al Gobierno el dictado de altas órdenes militares. Esta es una realidad que he contrastado. Cabe, pues, cuestionarse la pregunta de si es o no es una práctica adecuada a la Constitución.

A mi entender, el que el Rey adopte la iniciativa del coloquio constitucional con el Gobierno proponiendo a éste que adopte una alta orden militar no contradice ningún precepto constitucional $y$, por tanto, no es objetable.

No encuentro precepto constitucional alguno que prohiba que el Rey continúe con la práctica de iniciar el coloquio constitucional con el Gobierno proponiéndole el refrendo de una alta orden militar. Ciertamente que la prestación gubernamental del refrendo ministerial es voluntaria, con lo que se evidencia el predominio gubernamental en la desigualdad del acto regio refrendado, supuesto que, por el contrario, la firma regia de una orden de comando militar instada por el Gobierno a un acto regio debido. Sin embargo, es indudable que la iniciativa regia de una orden militar es un instrumento de extraordinaria importancia para el ejercicio por parte del Rey de su poder moderador ${ }^{14}$.

13 Entrevista que me concedió el General SABINO FERNÁNDEZ CAMPO, Secretario General de la Casa Real, en el Palacio de Marivent, Palma de Mallorca.

${ }_{14}$ Esta operativa del ejercicio por el Rey de su Comandancia militar ha sido 
Interesa, a este respecto, destacar que no se trata de una práctica novedosa en el Derecho Constitucional Comparado. Desarrollando los arts. 25 y 28 de la Constitución de Noruega, el Decreto real de 8 de marzo de 1963 regula precisamente las que denomina "decisiones reales en vía de comando" que no son sino órdenes militares que el Rey propone al refrendo del ministro de Defensa.

Mi posición al respecto ha sido criticada por el Prof. BLANCO VALDÉS ${ }^{15}$, si bien sus contraargumentos se limitan a un aspecto concreto de mi tesis, concretamente a aquel que defiende que una controversia violenta entre el Rey y el Gobierno a propósito del dictado de una alta orden militar "obligaría a que el Presidente presentase su dimisión, forzando el pronunciamiento de las Cortes Generales" ${ }^{16}$. Frente a esta opinión, el Prof. Blanco Valdés escribe: "En todo caso, es en la crítica a las conclusiones de Lafuente donde con mayor claridad puede apreciarse la incongruencia entre la tesis del mando real efectivo (sea éste entendido, insistimos, con mayor o menor amplitud) y la naturaleza parlamentaria de la forma de gobierno consagrada en la Carta Suprema española. Ciertamente, sostener que, en el supuesto de colisión entre el Jefe del Estado y el Gobierno en torno a un acto de alto mando militar, la solución debe producirse a partir de la dimisión del Presidente, es colocarse en las antípodas de un sistema parlamentario de gobierno para entrar de lleno nuevamente, en la práctica histórica de la monarquía constitucional: la práctica de la doble responsabilidad $y$, en consecuencia, de la doble confianza. Esta solución -evidentemente la única posible en tal supuesto si se descarta la abdicación del monarca- es no sólo contradictoria con todo el espíritu democrático y parlamentario que informa nuestro vigente sistema constitucional, sino también con la propia letra del texto de 1978, cuyo artículo 108 establece taxativamente que "el Gobierno responde solidariamente de su gestión política ante el Congreso de los Diputados..."”.

destacada por múltiples comentaristas políticos, especialmente extranjeros. Destaca sobremanera el artículo, firmado por Jim HOAGLAND, y publicado en el diario Washington Post del 23 de septiembre de 1987 con motivo de la decisión española de exigir a los Estados Unidos la retirada de los cazas F-16 de la base aérea de Torrejón. En este artículo, además de asegurar que el Rey no ocultaba su disconformidad con la política del Presidente González al respecto, resaltaba la importancia de rol militar del Rey: "El Rey mantiene un profundo interés por los asuntos militares, interés que ayudó a salvar la joven democracia española de 1981 cuando él hizo frente al intento de golpe de Estado iniciado por un grupo de viejos oficiales militares. Los diplomáticos dicen que juega uno de los principales papeles en las decisiones militares españolas». (La traducción está tomada del madrileño Diario 16 de 25 de septiembre de 1987).

15 Roberto L. BLANCO VALDÉs, op. cit., págs. 129 a 136.

16 V. José M. ${ }^{a}$ Lafuente Balle, op. cit., pág. 391. 
Mi réplica a la crítica me obliga a calificar a ésta de superficial por juridicista. Ante una colisión en el coloquio constitucional entre el Rey y Gobierno no cabe aplicar reglas exclusivamente jurídicas como pretende el Prof. BLANCO VALDÉS, según el cual, mientras que en la Monarquía constitucional debía ceder el Gobierno, en la Monarquía parlamentaria debe ceder el Rey. Es cierto que este principio de predominio gubernamental rige en los textos constitucionales de las Monarquías parlamentarias occidentales. Sin embargo, la práctica política ha sido muchísimo más rica y sutil que los preceptos jurídicos que, como siempre sucede en estos casos, han resultado desbordados.

El aún reciente conflicto que enfrentó en Bélgica al Rey Balduino con el Gobierno, a resultas de la negativa de aquél a sancionar la ley de despenalización del aborto, no se solucionó con la destitución del Rey conforme habrían exigido los principios jurídicos de la Monarquía parlamentaria. Antes al contrario, las valoraciones políticas del conflicto obligaron a idear para el caso soluciones extrañas y de dudosa virtualidad técnico-jurídica, como fue la inhabilitación temporal del Rey.

Ante una conjetura semejante en la que, iniciado el coloquio constitucional a instancias del Rey, éste entrase en conflicto con el Gobierno, no me parece razonable defender que la solución vendría dada por la simple aplicación de los principios constitucionales propios de la Monarquía parlamentaria porque, sencillamente, no ha sucedido así en otros precedentes históricos similares. Por otra parte, ningún texto constitucional regula la forma en que el Rey debería ser cesado. El Prof. BLANCO VALDÉS propone que esta forma debería de ser la de la abdicación, pero éste es un acto estrictamente voluntario de los monarcas europeos. Tampoco parece que la inhabilitación pudiese dar forma al cese del Rey porque esta figura está constitucionalmente restriñida al supuesto de que el Rey estuviese imposibilitado para el ejercicio de su autoridad (art. 59).

Por estas razones, defendi y defiendo que la solución de un conflicto semejante entre el Rey y el Gobierno no vendría dada por la aplicación estricta de la normativa constitucional, sino por una serie de parámetros políticos, concretamente: el carácter secreto o público del coloquio, la importancia de la mayoría parlamentaria que apoyase al Gobierno y la auctoritas del Rey.

No cuestiono que, en una Monarquía parlamentaria como la que se regula en la Constitución española, la decisión última corresponde a las Cortes Generales. Simplemente afirmo que en caso de producirse un supuesto de conflicto semejante entre el Rey y el Gobierno, la solución no vendría dada por la sola aplicación de la normativa jurídico-constitucional. 
No obstante nuestra polémica, estoy seguro de que el prof. BLANCO VALDÉS coincidiría conmigo en que, en cualquier caso, la prudencia con que el Rey debe desempeñar su cargo debería ser suficiente como para que estos conflictos no se produjesen. En este sentido y comentando mi afirmación de que el Gobierno nunca ha negado el refrendo a las iniciativas regias, el Prof. TORRES DEL MORAL ${ }^{17}$ escribe: "Digamos que así ha sido por fortuna. El Gobierno nunca ha planteado problemas, sin duda por la prudencia de las medidas que el Rey propone. Pero iy si discrepa y niega el refrendo? Lo deseable sería que, en tal hipótesis, el Rey se replegaran.

\section{IV. ¿UNA REFORMA DEL ART. $62 . h ?$}

Desarrollada la cuestión, no cabe sino preguntarse sobre la hipotética conveniencia de reformar el texto del artículo $62 . h$ de la Constitución. Tres son las alternativas: la supresión, la reforma o el mantenimiento del texto.

Probablemente por razones políticas ningún autor ha defendido la conveniencia de suprimir el art. $62 . h$ de la Constitución al modo del Instrumento de Gobierno dictado en Suecia en 1974. Ciertamente la realidad política española está muy alejada de la sueca y una medida semejante seria de muy dudosa oportunidad política.

Aunque el Prof. DE OTTO Y PARDO no se manifiesta en este sentido, entiendo que su teoría vendría mucho más fundamentada si el artículo 62.h atribuyese al Rey, no ya el mando supremo de las Fuerzas Armadas, sino el rango de Jefe de las Fuerzas Armadas, porque, en tal caso, el Rey estaría atribuido de un grado militar en el que fundamentar su potestad de dar órdenes a los militares de grado inferior.

A mi entender, no existe razón alguna para reformar el texto del artículo 62.h. Razones históricas y políticas justifican que el Rey tenga una función militar siquiera que ésta sea eminente, es decir, meramente honorífica y simbólica.

17 Antonio Torres del Moral, op. cit., vol. 2, pág. 49. 